\title{
DISCUSSION
}

\section{The effect of the development of undrained pore pressure on the efficiency of compaction grouting}

\author{
N. KOVACEVIC, D. M. POTTS and P. R. VAUGHAN (2000). \\ Géotechnique 50, No. 6, 683-688
}

\section{G. Jefferies and D. A. Shuttle, Golder Associates}

The authors state that the effect of excess pore water pressures caused by relatively rapid grout injection is that the efficiency of treatment may be reduced substantially. This may be alternatively expressed to say that fully drained conditions appear to be essential for effective densification by grouting. We suggest that this is too strong a conclusion, and possibly a consequence of the chosen soil model and initial conditions. Other simulations suggest that good levels of densification may be achieved under partially drained conditions, and this approach may be more cost-effective and practical than injecting slowly enough to achieve a fully drained grout injection when dealing with silty soils. We offer the following example.

In 1997 two sinkholes developed in the core of Bennett Dam in British Columbia. This dam is some $200 \mathrm{~m}$ high, retaining a reservoir (Lake Williston) 235 miles long $(380 \mathrm{~km})$, and provides as much as a third of the electrical power to British Columbia. The appearance of the sinkholes caused much concern, instigating immediate intensive investigations and, eventually, the use of compaction grouting to restore the integrity of the dam core. Stewart et al. (1997) provide an overview of the occurrence of the sinkholes and their investigation, while Garner et al. (2000) discuss the selection of compaction grouting and its implementation as the remediation.

Because of the importance of the dam, and its potential to affect large numbers of people, compaction grouting was required to be controlled and engineered. Further, the results obtained at each stage were to be analysed in near real time so as to obtain assurance that compaction was proceeding as expected. The discussers' company was retained for the prediction and analysis of this compaction grouting.
As in the authors' paper, radial symmetry was adopted for the analysis, with a large-strain formulation. Details of the numerical formulation are given in Shuttle \& Jefferies (1998), and an overview of the modelling of compaction grouting is in Shuttle \& Jefferies (2000). However, our work differed in two respects: the representation of drainage, and the range of constitutive behaviour modelled. We also examined the issue of radial idealisation, but used the more conventional approach of comparing cylindrical and spherical symmetry rather than the comparison of cylindrical plane strain and plane stress used by the authors. Trials using inclinometers in the influence zone of compaction grouting at Canoe Pass as part of the preparatory work for the dam remediation showed that the cylindrical plane strain idealisation was a good approximation for at least the primary pass of compaction grouting.

We represented drainage as the full spectrum of drained through to undrained using a standard coupled Biot formulation (Smith \& Griffiths, 1988). This allowed us to investigate the full range of grout injection rates. We represented the soil being compacted with the NorSand model. This allowed us to investigate loose to compact sands with realistic constitutive behaviour, and in particular including the familiar S-shaped stress paths exhibited by such soils under undrained conditions. Note that Cam Clay is a particular case of NorSand, so that the model used by the authors can be captured by appropriate choice of parameters and initial conditions with the approach presented. It is this choice of initial conditions that leads to rather different results from those of the authors.

In the case of Bennett dam the sinkhole soils (sandy silts) were not as loose as would be represented by normally consolidated modified Cam Clay. Rather, testing showed that dam

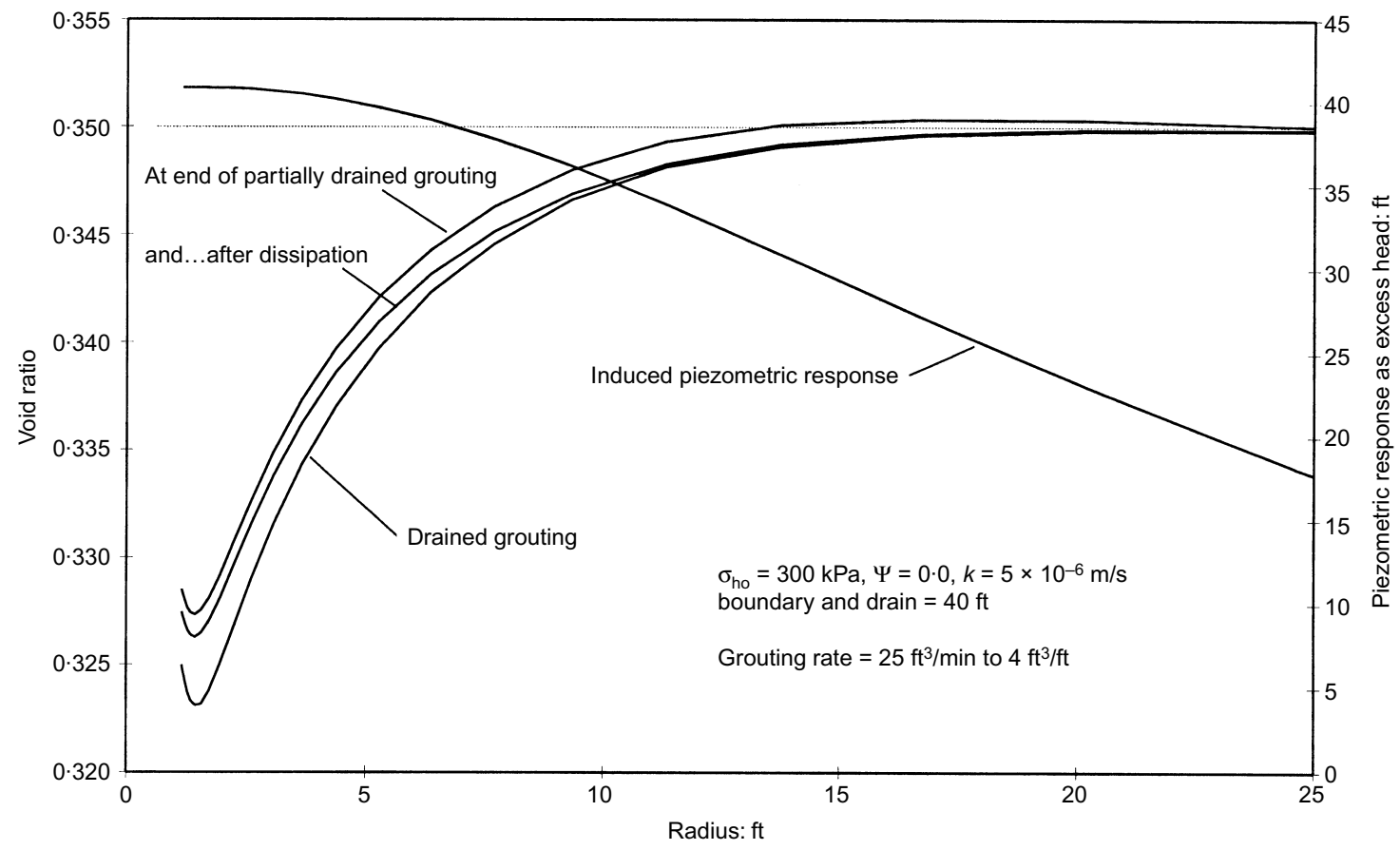

Fig. 9. Distribution of void ratios and excess pore water pressure after grouting to $4 \mathrm{ft}^{3} / \mathrm{ft}^{\text {at }} 0 \cdot 25 \mathrm{ft}^{3} / \mathrm{min}^{2}$ 
core soils in the sinkhole were essentially at the critical state, consistent with their vertical movement of many metres. This was captured in our simulations. An example of results obtained is shown in Fig. 9, this simulation being for a grout injection rate of $0.25 \mathrm{ft}^{3} /$ min up to a maximum injected volume of $4 \mathrm{ft}^{3}$ per $\mathrm{ft}$ of grout hole (imperial units are given consistent with North American grouting practice). This injection rate was at the slowest end of the desired operating range.

Figure 9 shows both the void ratio distribution (left-hand axis) and excess pore water pressure distribution (right-hand axis) against distance from the centreline of the grout hole. Three void ratio distributions are plotted: on completion of injection, after consolidation, and what would have been achieved by drained injection. In contrast to the authors' results, compaction is surprisingly efficient, even with a peak excess pore water head of $40 \mathrm{ft}$. Expressed in terms of the initial vertical effective stress, this is an excess pore pressure ratio of $0 \cdot 4$.

It follows from Fig. 9 that the authors' conclusion that high excess pore water pressures are associated with ineffective compaction is too sweeping. Depending on the initial conditions, material state and material properties, reasonably effective compaction may be achieved despite quite substantial excess pore water pressures. Having said that, we did conclude that grout injection rates as low as $0.25 \mathrm{ft}^{3} /$ min were required at Bennett Dam.

\begin{abstract}
Authors' reply
The authors thank Jefferies and Shuttle for their interesting discussion. They had not been aware of this work. The authors see no significant disagreement between their approach and conclusions and those of Jefferies and Shuttle. The authors considered the limiting cases of drained behaviour, when volumetric compression occurs during injection and compaction grouting is fully efficient, and undrained behaviour, when volumetric compression occurs only after treatment as the soil consolidates. In the latter case treatment is much less efficient. It is perhaps self-evident that intermediate behaviour, in which partial consolidation occurs during injection, will result in compression that lies between the two limits, although this is not stated in the paper. The authors quoted the field data from Boulanger \& Hayden (1995) for Sacramento silt (Figs 1 and 8
\end{abstract}

of the paper), which show quite effective treatment despite the development of excess pore pressure. The authors think that, if the same material assumptions were made, their analyses and that of Jefferies and Shuttle would give similar results. The authors agree that effective treatment can be achieved without full consolidation during treatment. This may be a cost-effective approach. However, if only partial consolidation is occurring during treatment, then a relatively small change in permeability may give a rather larger change in the efficiency of treatment.

Compaction grouting has grown up as a semi-empirical procedure. It is not normally applied except in materials that would largely consolidate during treatment, although this has not been given as a specific limitation to the treatment. This limit has not been put on a qualitative or theoretical basis. Thus there has been a risk that this limit would be unappreciated or forgotten. Indeed, the work done by the authors was stimulated by proposals to use compaction grouting in a loose moraine soil in which significant consolidation during treatment was unlikely. The work of Jefferies and Shuttle and the work of the authors show that such a process can be analysed numerically. The type of material in which it can be effective can then be established quantitatively. The authors believe that this is a much safer way forward than reliance on experience empirically formulated.

\section{REFERENCES}

Boulanger, R. W \& Hayden, R. R. (1995). Aspects of compaction grouting of liquefiable soil. J. Geotech. Engng Div., ASCE 121, No. $12,844-855$.

Garner, S. J., Warner, J., Jefferies, M. G. and Morrison, N. A. (2000). A controlled approach to deep compaction grouting at WAC Bennett Dam. Proc. 53rd Can. Geotech. Conf., Montreal.

Shuttle, D. A. \& Jefferies, M. G. (1998). Dimensionless and unbiased CPT interpretation in sand. Int. J. Numer. Anal. Meth. Geomech. 22, 351-391.

Shuttle, D. A. \& Jefferies, M. G (2000). Prediction and validation of compaction grout effectiveness. Proc. Wallace Baker Memorial Symposium, ASCE GeoDenver Conf.

Smith, I. M. \& Griffiths, V. (1988). Programming the finite element method. Wiley.

Stewart, R. A., Watts, B. D., Sobkowicz, J. C. and Kupper, A. (1997). Geotechnical News 15, No. 2, 32-42. 